\title{
Digestibilidades parcial e total de dietas com feno de capim-marandu e concentrado balanceadas para diferentes níveis de produção ${ }^{1}$
}

\author{
Rodolfo Marques de Brito ${ }^{2}$, Alexandre Amstalden Moraes Sampaio ${ }^{3}$, Alexandre Rodrigo \\ Mendes Fernandes ${ }^{4}$, Wignez Henrique ${ }^{5}$, José Wanderley Cattelan ${ }^{6}$, Karina de Souza \\ Routman ${ }^{7}$
}

\footnotetext{
${ }_{1}$ Parte da tese do primeiro autor apresentada à FCAV/Unesp/Jaboticabal.

2 Doutor pela FCAV/Unesp/Jaboticabal.

${ }^{3}$ Departamento de Zootecnia/FCAV/Unesp, Jaboticabal, SP. Bolsista CNPq

${ }^{4}$ Doutorando pela FCAV/Unesp/Jaboticabal.

5 Instituto Zootecnia, São José do Rio Preto, SP.

${ }^{6}$ Departamento de Clínica e Cirurgia Veterinária/FCAV/Unesp, Jaboticabal, SP.

${ }^{7}$ Mestre pela FCAV/Unesp/Jaboticabal.
}

RESUMO - O experimento foi realizado com o objetivo de avaliar as digestibilidades parcial e total das frações digestíveis de dietas com feno de capim-marandu e concentrado utilizando-se a fibra em detergente ácido indigestível como indicador Foram utilizados quatro tourinhos da raça Santa Gertrudes, canulados no rúmen e duodeno, distribuídos em delineamento quadrado latino $4 \times 4$. As dietas foram ajustadas para que os animais tivessem ganhos diários de peso corporal (GPC) de 0,5 e $1 \mathrm{~kg} /$ animal, associado a potenciais de fermentação microbiana de 9,5 e $11 \mathrm{~g}$ de PB microbiana/MJ EM fermentável. Houve efeito das dietas ajustadas para potencial de GPC sobre as ingestões diárias de MS (7,05 e 8,07 kg/animal, respectivamente para 0,5 e 1,0 kg/animal de GPC), mas não daquelas balanceadas para potencial de fermentação microbiana $(7,57 \mathrm{~kg} / \mathrm{animal})$ O tratamento para GPC diário de $1 \mathrm{~kg} /$ animal proporcionou maior digestibilidade total da matéria orgânica e de carboidratos totais (médias de 66,63 e 58,68\%, respectivamente) quando comparado ao tratamento para GPC diário de 0,5 kg/animal, que apresentou, para as mesmas variáveis, médias de 61,57 e 53,94\%. Os resultados não justificaram a utilização de dietas para maior potencial de fermentação microbiana. As dietas balanceadas para altos ganhos de peso, no entanto, mostraram-se melhores quanto à ingestão e ao aproveitamento dos nutrientes que as formuladas para baixos ganhos de peso.

Palavras-chave: fibra em detergente ácido indigestível, ganho de peso, potencial de síntese microbiana

\section{Partial and total tract digestibility of diets containing Brachiaria brizantha cv. Marandu hay plus concentrate balanced for different levels of production}

\begin{abstract}
The objective of this trial was to evaluate partial and total tract digestibilities of diets containing Brachiaria brizantha hay plus concentrate fed to young bulls. Four Santa Gertrudis young bulls fitted with duodenal and ruminal cannulae were used in a 4 x 4 Latin square. Diets were formulated to yield daily body weight gains (BWG) of 0.5 or $1 \mathrm{~kg} / \mathrm{animal}$ and potential of microbial fermentation of 9.5 or $11 \mathrm{~g}$ of microbial crude protein/MJ fermentable metabolizable energy. Apparent digestibility of nutrients was estimated using indigestible acid detergent fiber (IADF) as the internal marker. Dry matter intake (DMI) of bulls fed the diet formulated to yield high BWG was greater $(8.07 \mathrm{~kg} /$ day $)$ than the DMI of bulls fed the low BWG diet, which averaged $7.05 \mathrm{~kg} / \mathrm{animal} /$ day. However, DMI did not differ and averaged $7.57 \mathrm{~kg} / \mathrm{animal} /$ day on diets formulated to yield different potential of microbial fermentation in the rumen. Diet formulated to yield BWG of $1 \mathrm{~kg} /$ animal had greater total tract digestibilities of $\mathrm{OM}$ and total carbohydrates than that formulated to yield BWG of $0.5 \mathrm{~kg} / \mathrm{animal}$. Results from this trial did not justify formulating diets for greater ruminal microbial fermentation. On the other hand, diet balanced for high BWG improved intake and nutrient utilization compared to that balanced for low BWG
\end{abstract}

Key Words: body weight gain, indigestible acid detergent fiber, potential of microbial fermentation

\section{Introdução}

Volumosos de baixa qualidade são importantes fontes de nutrientes na alimentação dos ruminantes (Ítavo et al., 2002a). Na estação seca, os bovinocultores dos países tropicais geralmente dispõem apenas de áreas de gramíneas com qualidade deste tipo. Para otimizar a utilização desse material e manter o desempenho animal em níveis satisfatórios, geralmente é necessário aumentar o aporte de nutrientes digestíveis na dieta e promover maior ingestão 
e digestão do alimento por meio do fornecimento de nutrientes suplementares.

No Brasil, a maior parte da produção bovina está fundamentada em pastagens formadas por espécies de Brachiaria, estimando-se ganho médio anual de $0,25 \mathrm{~kg} /$ animal $/$ dia, mas com variações de $-0,5 \mathrm{a}+1,0 \mathrm{~kg} /$ animal $/ \mathrm{dia}$ entre as estações seca e chuvosa (Anualpec, 2004).

Reduzir os efeitos das deficiências nutricionais das pastagens por meio da suplementação, cujo objetivo básico é fornecer nutrientes específicos da dieta do animal e atenuar os limites impostos pela variação estacional na produção forrageira, torna-se um grande desafio para os pesquisadores brasileiros. Suprir as deficiências e não sobrepor o valor nutritivo da forragem é fator decisivo para que a estratégia de suplementação seja viável.

Se o objetivo do produtor é a terminação do animal ao final da estação seca por meio de ganhos diários acima de $0,5 \mathrm{~kg} /$ animal, a quantidade de suplemento necessária é em torno de $1 \%$ do peso corporal do animal - acima deste nível de suplementação, o custo do ganho adicional por unidade de suplemento passa a comprometer a rentabilidade da atividade (San Thiago \& Silva, 1998). Sob este ponto de vista, a suplementação em semiconfinamento no período da seca tem se destacado na preferência dos produtores (Anualpec, 2004).

Para alcançar resultados satisfatórios em sistemas e suplementação em pastagem de baixa qualidade, é necessário conhecer os fatores que afetam a microbiota ruminal, que representa a essência da interação simbiótica. Avaliar os efeitos da manipulação da dieta e o aproveitamento das frações nutritivas quanto à degradação microbiana e à digestão pós-ruminal é requisito primário para avançar na compreensão dos mecanismos de controle deste sistema que garante aos herbívoros relativo sucesso no processo produtivo. Além disso, quando os animais têm forragem disponível e recebem concentrado suplementar, é preciso considerar que a suplementação pode produzir efeitos aditivo ou substitutivo em relação à forragem (Euclides et al., 1997).

$\mathrm{Na}$ avaliação técnico-nutricional do desempenho animal, o suprimento protéico microbiano tem sido alvo de estudos e sua estimativa incorporada aos sistemas de avaliação de dietas: ARC (1984), AFRC (1993), NRC (1996) e CNCPS (Fox et al., 1992).

O objetivo neste trabalho foi avaliar as digestibilidades parcial e total dos nutrientes de dietas com feno de capim Brachiaria brizantha cultivar Marandu e concentrados, balanceadas para proporcionar dois níveis de ganho de peso, associados a dois potenciais de síntese microbiana, em tourinhos da raça Santa Gertrudes. No experimento, foi simulado o pastejo por animais durante a estação seca recebendo suplementação com concentrado em regime de semiconfinamento.

\section{Material e Métodos}

O ensaio foi conduzido no Setor de Bovinocultura de Corte e no Laboratório de Ruminantes na Faculdade de Ciências Agrárias e Veterinárias - Unesp, campus de Jaboticabal, na região norte do estado de São Paulo $\left(21^{\circ} 15^{\text {, }}\right.$ 22 " de latitude sul e $48^{\circ} 18^{\prime} 58^{\prime \prime}$ ' de longitude oeste). A altitude local é de 595 m e o clima, segundo a classificação de Köppen, é do tipo subtropical, com chuvas de verão e inverno relativamente seco. As médias anuais de precipitação pluviométrica, temperatura e umidade relativa do ar foram calculadas em $1.400 \mathrm{~mm}, 21^{\circ} \mathrm{C}$ e $70 \%$, respectivamente.

A pastagem de capim Brachiaria brizantha cultivar Marandu selecionada para confecção do feno utilizado nas dietas permaneceu sob pastejo durante o período chuvoso e recebeu adubação de manutenção de $130 \mathrm{~kg}$ de nitrogênio/ha, parcelada em quatro aplicações. Após o período de adubação, seguido de um ciclo de pastejo com desfolha de intensidade média, a área foi vedada ao acesso dos animais por 30 dias, antes do processo de fenação. Com isso, pretendeu-se neste experimento simular a alimentação dos animais em pastejo durante a estação seca.

Foram utilizados quatro tourinhos Santa Gertrudes com $380 \mathrm{~kg}$ de PV e 17 meses de idade. Os animais foram canulados no rúmen e no duodeno proximal, segundo técnica descrita por Leão \& Coelho da Silva (1980), e receberam os tratamentos necessários no pré e pós-operatório, a fim de garantir a plena recuperação do processo cirúrgico.

Após a recuperação completa da cirurgia para implantação das cânulas de rúmen e duodeno, cada animal foi alojado em baia individual de alvenaria de $16 \mathrm{~m}^{2}$, dotada de cocho, bebedouro e saleiro exclusivos. Foram avaliadas quatro dietas experimentais (Tabelas 1 e 2), balanceadas para proporcionarem dois potenciais de fermentação microbiana (y) - alto (11 g de PB microbiana/MJ de EM fermentável) e baixo (9,5 g de PB microbiana/MJ de EM fermentável) - e propiciarem ganhos diários de peso corporal (GPC) de 0,5 e 1,0 kg/animal (AFRC, 1993).

Este trabalho fez parte de um conjunto de experimentos (Brito, 2004) nos quais foi simulada a atividade de pastejo por bovinos mantidos em pastagem de Brachiaria brizantha cv. Marandu durante a estação seca recebendo concentrado na forma de suplementação, em regime de semiconfinamento. 
O período experimental teve duração de 64 dias, subdivididos em quatro períodos de 16 dias de experimentação, sendo os sete primeiros dias de adaptação à dieta, dois dias de coleta de fezes e digesta duodenal, dois dias de coleta de conteúdo ruminal, e os últimos quatro dias de incubação in situ. As bases do protocolo experimental seguiram as indicações de Fu et al. (2001) e Ítavo et al. (2002 a, b, c, e).

Durante todo o período experimental, os animais receberam feno ad libitum, parcelado em duas refeições diárias (7 e 17h), e concentrado fornecido apenas na primeira refeição do dia, de acordo com cada tratamento. Os animais foram pesados no início e ao final do ensaio.

Todos os dias pela manhã, as sobras de alimento nos cochos foram quantificadas e amostradas de forma representativa, para controle da quantidade de alimento consumida pelos animais. As amostras diárias formaram uma amostra composta por animal e por período e permaneceram acondicionadas em congelador a $-20^{\circ} \mathrm{C}$.
A digestão dos nutrientes foi estimada utilizando-se a fibra em detergente ácido indigestível (FDAi) como indicador interno (Penning \& Jonhson, 1983). A estimativa da digestões total e parcial das frações nutritivas das rações foi realizada conforme recomendações de Sampaio et al. (2000) e Berchielli et al. (2000), observando-se as modificações propostas por Ítavo et al. (2002e).

A digesta duodenal foi coletada via cânula e as fezes, diretamente do piso, às $10 \mathrm{~h}$ no primeiro dia e às $16 \mathrm{~h}$ no segundo dia de coleta. Optou-se pela coleta de fezes do piso para reduzir o estresse causado em alguns animais pela coleta no reto. Este procedimento não trouxe prejuízo à qualidade e ao horário da coleta, pois o piso foi lavado com água nos dias de coleta e os animais defecavam em quantidade suficiente logo após sua contenção por meio de cabrestos.

Em seguida, as amostras foram acondicionadas em sacos plásticos e mantidas a $-20^{\circ} \mathrm{C}$, devidamente

Tabela 1 - Composição bromatológica dos ingredientes utilizados nas dietas Table 1 - Chemical composition of the experimental feeds

\begin{tabular}{|c|c|c|c|c|c|c|c|c|}
\hline $\begin{array}{l}\text { Ingrediente } \\
\text { Ingredient }\end{array}$ & $\begin{array}{l}\text { MS } \\
D M\end{array}$ & $\begin{array}{c}\mathrm{MO} \\
O M\end{array}$ & $\begin{array}{l}\mathrm{PB} \\
C P\end{array}$ & $\mathrm{EE}$ & $\begin{array}{c}\text { Cinzas } \\
\text { Ash }\end{array}$ & $\begin{array}{l}\mathrm{CT} \\
T C\end{array}$ & $\begin{array}{l}\text { FDN } \\
N D F\end{array}$ & $\begin{array}{l}\mathrm{FDA} \\
A D F\end{array}$ \\
\hline & $(\%)$ & & & & $\begin{array}{c}\% \text { da MS } \\
\% D M\end{array}$ & & & \\
\hline Feno capim-marandu (Palisadegrass hay) & 90,08 & 94,72 & 5,65 & 0,74 & 5,28 & 88,32 & 81,55 & 47,54 \\
\hline Milho em grão moído (Ground corn) & 87,27 & 99,40 & 11,10 & 3,92 & 0,60 & 84,38 & 26,86 & 4,23 \\
\hline Farelo de algodão (Cottonseed meal) & 89,96 & 93,79 & 45,81 & 1,36 & 6,21 & 46,62 & 28,42 & 20,66 \\
\hline
\end{tabular}

Tabela 2 - Composição dos concentrados e características das dietas experimentais

Table 2 - Ingredient composition of concentrates and chemical composition of the experimental diets

\begin{tabular}{|c|c|c|c|c|}
\hline \multirow[t]{2}{*}{$\begin{array}{l}\text { Composição dos concentrados (\%) } \\
\text { Concentrate composition (\%) }\end{array}$} & \multicolumn{2}{|c|}{$\begin{array}{c}\text { Baixo } \mathrm{GPC}^{1} \\
\text { Low } B W G^{1}\end{array}$} & \multicolumn{2}{|c|}{$\begin{array}{l}\text { Alto GPC } \\
\text { High } B W G\end{array}$} \\
\hline & $\begin{array}{c}\text { Baixo } \mathrm{y}^{2} \\
\text { Low } y^{2}\end{array}$ & $\begin{array}{l}\text { Alto y } \\
\text { High } y\end{array}$ & $\begin{array}{l}\text { Baixo y } \\
\text { Lowy }\end{array}$ & $\begin{array}{l}\text { Alto y } \\
\text { High y }\end{array}$ \\
\hline Milho em grão moído (Ground corn) & 47,4 & 33,3 & 50,8 & 27,8 \\
\hline Farelo de algodão (Cottonseed meal) & 20,7 & 20,7 & 13,1 & 13,1 \\
\hline Farelo de soja (Soybean meal) & 5,8 & 19,9 & 19,6 & 42,6 \\
\hline Soja em grão moído (Ground soybean) & 22,8 & 22,8 & 14,4 & 14,4 \\
\hline Mistura mineral ${ }^{3}$ (Mineral mix) & 3,3 & 3,3 & 2,1 & 2,1 \\
\hline \multicolumn{5}{|l|}{$\begin{array}{l}\text { Características da dieta } \\
\text { Chemical composition of the diet }\end{array}$} \\
\hline Proteína bruta (\% da MS) (Crude protein, \% of DM) & 11,8 & 13,6 & 14,3 & 15,2 \\
\hline Energia metabolizável (MJ/kg de MS) (Metabolizable energy, MJ/kg of DM) & 9,4 & 9,4 & 10,1 & 10,0 \\
\hline
\end{tabular}

1 GPC - Ganho diário estimado de peso corporal: alto (1 kg/animal) e baixo $(0,5 \mathrm{~kg} / \mathrm{animal})$.

2 y - Potencial estimado de fermentação microbiana: alto $(11 \mathrm{~g}$ de proteína bruta microbiana/MJ de energia metabolizável fermentável) e baixo $(9,5 \mathrm{~g}$ de proteína bruta metabolizável/MJ de energia metabolizável fermentável).

1 BWG - Estimated daily body weight gain: high (1 kg/animal) and low $(0.5 \mathrm{~kg} / \mathrm{animal})$

2 Estimated potencial of microbial fermentation: high (11 g of microbial crude protein/MJ of fermentable metabolizable energy) and low (9.5 g of microbial crude protein/MJ of fermentable metabolizable energy).

${ }^{3}$ Niveis de garantia por kg (Levels of garantee per kg): Ca $-271 \mathrm{~g}, \mathrm{P}-29 \mathrm{~g}, \mathrm{Mg}-20 \mathrm{~g}, \mathrm{~S}-31 \mathrm{~g}, \mathrm{Na}-62 \mathrm{~g}, \mathrm{Zn}-1.350 \mathrm{mg}, \mathrm{Cu}-340 \mathrm{mg}, \mathrm{Fe}-1.064 \mathrm{mg}$, $\mathrm{Mn}-940 \mathrm{mg}$, Co - $10 \mathrm{mg}, \mathrm{I}-25 \mathrm{mg}$ e Se - $10 \mathrm{mg}$. 
identificadas. Ao final deste período, cada amostra de digesta e fezes foi liofilizada, moída e analisada quanto à FDAi, após a composição de amostras por animal e por período. A determinação da FDAi é realizada visando estimar a quantidade produzida de digesta e de fezes. A análise da FDAi foi feita após 144 horas de incubação do material no rúmen (Penning \& Jonhson, 1983). As amostras de digesta e fezes processadas, juntamente com as de alimento e sobras, também foram encaminhadas ao laboratório para análise de MS, PB, cinzas, EE e CT, segundo AOAC (1995), além de FDN e FDA, conforme Van Soest \& Wine (1998). Foi estimado o teor de MO pela diferença obtida com o teor de cinzas e CT, conforme Sniffen et al. (1992), a fim de possibilitar a determinação da ingestão, do fluxo e da excreção de nutrientes pelo animal, bem como o coeficiente de digestibilidade dos nutrientes.

As médias foram analisadas em delineamento de quadrado latino 4 x 4 (animais x períodos), com quatro tratamentos, em esquema fatorial 2 x 2 (GPC x y). Foi realizada análise de variância pelo teste F a 5\% (Sampaio, 1998), utilizando-se o SAS (2001).

\section{Resultados e Discussão}

Os resultados de consumo de feno, concentrado, MS e MO estão listadas na Tabela 3. Para as variáveis apresentadas nessa tabela, não foi verificada interação significativa $(\mathrm{P}>0,05)$ entre potencial de ganho de peso corporal e poten- cial de fermentação microbiana. Assim, esses fatores foram analisados separadamente.

Não houve diferença $(\mathrm{P}>0,05)$ na ingestão diária absoluta de MS de feno (kg/animal) quando considerado o potencial de fermentação. No caso do potencial de GPC, houve menor ingestão absoluta $(\mathrm{P}<0,05)$ de feno quando oferecida maior quantidade de concentrado ao animal, sem reflexo na ingestão relativa de feno calculado como porcentagem do peso corporal (PC).

Houve ingestão diária total do concentrado pelos animais durante todo o período experimental. Quando avaliada a ingestão de concentrado em relação ao peso corporal dos animais, ficou evidenciada maior $(\mathrm{P}<0,05)$ ingestão nos animais que receberam o tratamento para alto GPC. Não houve diferenças $(\mathrm{P}>0,05)$ entre os tratamentos para diferentes potenciais de fermentação, que apresentaram média diária de $0,76 \%$ do PC.

As médias de ingestão total de MS e MO foram maiores $(\mathrm{P}<0,05)$ nos animais recebendo maior quantidade de concentrado, visando maior GPC, mesmo quando avaliada sob diferentes formas de expressão do consumo pelo animal. Bürguer et al. (2000) obtiveram ingestões diárias de MS de 115,87 e 99,64 g/kg de PC 0,75 em bezerros de $107 \mathrm{~kg}$ recebendo feno de coastcross suplementado com milho e farelo de soja nos níveis de 30 e 42,5\% da MS, respectivamente. Embora esses animais fossem mais jovens, mostraram consumo mais elevado que os animais deste experimento. Dias et al. (2000) forneceram feno de coastcross

Tabela 3 - Ingestão diária de feno, concentrado, MS e MO por tourinhos Santa Gertrudes recebendo feno de capim-marandu e concentrado para diferentes potenciais de fermentação e produção

Table 3 - Daily intakes of hay, concentrate, DM and OM on Santa Gertrudis young bulls fed diets containing palisadegrass hay plus concentrate formulated to yield different potential of microbial protein fermentation

\begin{tabular}{|c|c|c|c|c|c|c|c|}
\hline \multirow[t]{2}{*}{$\begin{array}{l}\text { Ingestão } \\
\text { Intake }\end{array}$} & \multicolumn{2}{|c|}{$\begin{array}{l}\mathrm{GPC}^{1} \\
B W G^{1}\end{array}$} & \multirow[b]{2}{*}{$\mathrm{F}$} & \multicolumn{2}{|c|}{$\mathrm{y}^{(2)}$} & \multirow[b]{2}{*}{$\mathrm{F}$} & \multirow[t]{2}{*}{$\mathrm{CV}^{3}(\%)$} \\
\hline & $\begin{array}{c}\text { Baixo } \\
\text { Low }\end{array}$ & $\begin{array}{l}\text { Alto } \\
\text { High }\end{array}$ & & $\begin{array}{c}\text { Baixo } \\
\text { Low }\end{array}$ & $\begin{array}{l}\text { Alto } \\
\text { High }\end{array}$ & & \\
\hline MS de feno (kg/animal) (Hay, kg/animal) & 4,91 & 4,64 & $*$ & 4,77 & 4,79 & NS & 4,45 \\
\hline MS de feno $\left(\% \mathrm{PC}^{4}\right)\left(\right.$ Hay, \% $\left.B W^{4}\right)$ & 1,21 & 1,15 & $*$ & 1,17 & 1,18 & NS & 4,08 \\
\hline Concentrado $\left(\% \mathrm{PC}^{4}\right)$ (Concentrate, $\left.\% B W^{4}\right)$ & 0,59 & 0,95 & $*$ & 0,77 & 0,76 & NS & 2,29 \\
\hline MS total (kg/animal) (Total, $\mathrm{kg} /$ animal) & 7,05 & 8,07 & $*$ & 7,57 & 7,56 & NS & 2,81 \\
\hline MS total $\left(\% \mathrm{PC}^{4}\right)\left(\right.$ Total, $\left.\% B W^{4}\right)$ & 1,73 & 2,00 & $*$ & 1,86 & 1,87 & NS & 2,38 \\
\hline MS total $\left(\mathrm{g} / \mathrm{kg} \mathrm{PC} \mathrm{PC}^{0,75}\right)$ (Total, $\left.\mathrm{g} / \mathrm{kg} B W^{0.75}\right)$ & 77,78 & 89,55 & $*$ & 83,63 & 83,71 & NS & 2,44 \\
\hline MO total (kg/animal) (Total OM, $\mathrm{kg} /$ animal) & 6,67 & 7,74 & $*$ & 7,20 & 7,21 & NS & 2,80 \\
\hline
\end{tabular}

NS - não-significativo; * significativo a $5 \%$ de probabilidade pelo teste $\mathrm{F}$.

$1 \mathrm{GPC}$ - Ganho diário estimado de peso corporal: alto $(1 \mathrm{~kg} / \mathrm{animal})$ e baixo $(0,5 \mathrm{~kg} / \mathrm{animal})$

2 y - Potencial estimado de fermentação microbiana: alto (11 g de PB microbiana/MJ de EM fermentável) e baixo (9,5 g de PB metabolizável/MJ de EM fermentável).

$3 \mathrm{CV}$ - Coeficiente de variação.

4 PC - Peso corporal.

NS - not significant.; * -significant at $5 \%$ of probability by F test.

1 BWG - Estimated daily body weight gain: high (1 kg/animal) and low $(0.5 \mathrm{~kg} / \mathrm{animal})$.

2 Estimated potencial of microbial fermentation: high (11 g of microbial crude protein/MJ of fermentable metabolizable energy) and low (9.5 g of microbial crude protein/MJ of fermentable metabolizable energy).

${ }^{3} \mathrm{CV}$-coefficient of variation.

${ }^{4}$ BW-Body weight. 
para novilhos F1 Limousin-Nelore de $268 \mathrm{~kg}$ e obtiveram ingestão de MS de 1,37 e 1,47\% PC para dietas contendo 30 e $42,5 \%$ de concentrado, respectivamente, valores menores que a média obtida neste ensaio. É possível calcular, pelos resultados da Tabela 3, que as porcentagens de concentrado dos tratamentos neste trabalho foram de 30 e $42 \%$ para baixo e alto GPC, respectivamente, e de $36 \%$ para os dois potenciais de fermentação microbiana.

Em nenhum dos casos avaliados, houve diferenças relativas entre tratamentos para os diferentes potenciais de fermentação microbiana $(\mathrm{P}>0,05)$. No entanto, Cardoso et al. (2000) complementaram a dieta de feno de coastcross para novilhos F1 Limousin x Nelore com níveis de concentrado que variaram de 25 a $75 \%$ da MS da dieta e obtiveram ingestão de MS similar entre os tratamentos, com médias de $1,58 \% \mathrm{PC}$ e $66,75 \mathrm{~g} / \mathrm{kg}$ de $\mathrm{PC}^{0,75}$. Véras et al. (2000) testaram níveis de concentrado entre 25 e $75 \%$ da MS em dietas à base de feno de Brachiaria decumbens e coastcross para tourinhos Nelore de $330 \mathrm{~kg}$. O consumo diário de MS foi similar entre os tratamentos tanto em \% do PC como em $\mathrm{g} / \mathrm{kg}$ de $\mathrm{PC}^{0,75}$, com médias de 2,14 e 94,87, respectivamente. No mesmo trabalho, o consumo diário de MO foi de 7,64 e $8,02 \mathrm{~kg}$ /animal para 30 e $42,5 \%$ de MS de concentrado na dieta, respectivamente, valores consideravelmente mais elevados que os obtidos neste experimento para os mesmos níveis de concentrado.

Os resultados de consumo de PB estão apresentados na Tabela 4 e os dos demais nutrientes estudados podem ser visualizados na Tabela 5. Embora o feno tenha sido fornecido à vontade, a suplementação com concentrado em diferentes níveis influenciou algumas dessas variáveis. Houve interação significativa (GPC $\times$ fermentação) na ingestão de PB, o que era esperado, pois este nutriente esteve diretamente relacionado à diferenciação dos tratamentos, com maiores níveis de ingestão nos casos de maior GPC e maior potencial de fermentação microbiana, considerando-se cada uma das causas de variação. O coeficiente de variação encontrado para a ingestão de PB foi de $0,59 \%$.

Observando-se ainda os diferentes potenciais de GPC, a ingestão de CT (Tabela 5) foi maior $(\mathrm{P}<0,05)$ nos tratamentos para maior GPC, visto que o conteúdo energético necessário ao maior nível de produção manteve estreita relação com o aporte de carboidratos e, eventualmente, com o de lipídeos. Assim, os animais do tratamento para alto GPC também ingeriram maior quantidade $(\mathrm{P}<0,05)$ de EE em relação ao tratamento para GPC mais baixo.

Para tourinhos Nelore de $330 \mathrm{~kg}$ recebendo feno de Brachiaria decumbens e coastcross e concentrado, Véras et al. (2000) verificaram ingestões diárias de PB, CT e EE de
0,$8 ; 7,17$ e $0,11 \mathrm{~kg} /$ animal para $30 \%$ de concentrado e de 1,00; 7,75 e $0,14 \mathrm{~kg} /$ animal para $42,5 \%$ de concentrado na MS da dieta, respectivamente. Os consumos de CT obtidos por esses autores foram superiores aos deste experimento, tanto para 30 quanto para $42 \%$ de concentrado.

Foi verificada maior $(\mathrm{P}<0,05)$ média no tratamento para alto GPC para ingestão relativa de FDN (\% do PC). A média deste ensaio ficou próxima à verificada por Resende et al. (2001ab), que alimentaram novilhos mestiços (5/8 Europeu com 24 meses de idade e $310 \mathrm{~kg}$ ), com feno de capimtanzânia em diferentes relações volumoso:concentrado. Esses autores concluíram que a maximização da ingestão de nutrientes digestíveis para a máxima eficiência de utilização da dieta ocorreu em níveis de ingestão de FDN entre 1,02 e 1,25\% PC, semelhantes ao citado pelo NRC (1984), de 1,2 $\pm 0,1 \%$ do PC. Quando a ingestão diária de FDN foi expressa em $\mathrm{kg}$ /animal ou em relação ao peso metabólico $\left(\mathrm{g} / \mathrm{kg}\right.$ de $\left.\mathrm{PC}^{0,75}\right)$, não foram observadas diferenças $(\mathrm{P}>0,05)$ entre os tratamentos para GPC, com médias diárias de $4,69 \mathrm{~kg} /$ animal e $51,86 \mathrm{~g} / \mathrm{kg}$ de $\mathrm{PC}^{0,75}$.

Dias et al. (2000) verificaram médias de ingestão diária de FDN de 0,9 e $0,68 \%$ do PC e de 30 e $27,2 \mathrm{~g} / \mathrm{kg}$ de $\mathrm{PC}^{0,75}$, para 30 e $42,5 \%$ de MS de concentrado na dieta, respectivamente, ao complementarem o feno de coastcross para novilhos F1 Limousin-Nelore de $286 \mathrm{~kg}$. Esses valores foram bem inferiores às médias verificadas neste estudo, sugerindo que a fração estimada como FDN pode,

Tabela 4 - Ingestão diária de PB (kg/animal) por tourinhos Santa Gertrudes recebendo feno de capim-marandu e concentrado para diferentes potenciais de fermentação e produção

Table 4 - Daily intake of CP (kg/animal) on Santa Gertrudis young bulls fed diets containing palisadegrass hay plus concentrate formulated to yield different potential of microbial protein fermentation

\begin{tabular}{llll}
\hline $\mathrm{GPC}^{1}$ & \multicolumn{2}{c}{$\mathrm{y}^{(2)}$} & \multirow{2}{*}{$\begin{array}{c}\text { Média } \\
\text { Average }\end{array}$} \\
\cline { 2 - 3 } & Baixo & Alto & \\
\cline { 2 - 3 } & Low & High & \\
\hline Baixo (Low) & $0,85 \mathrm{Bb}$ & $1,05 \mathrm{Ba}$ & 0,95 \\
Alto (High) & $1,22 \mathrm{Ab}$ & $1,43 \mathrm{Aa}$ & 1,32 \\
Média (Average) & 1,03 & 1,24 & \\
\hline
\end{tabular}

Médias seguidas de letras distintas, minúsculas (linha) e maiúsculas (coluna), diferem pelo teste $\mathrm{F}$ a $5 \%$ de probabilidade.

1 GPC - Ganho diário estimado de peso corporal: alto (1 kg/animal) e baixo (0,5 kg/animal).

2 y - Potencial estimado de fermentação microbiana: alto $(11 \mathrm{~g}$ de PB microbiana/MJ de EM fermentável) e baixo ( $9,5 \mathrm{~g}$ de PB metabolizável/ MJ de EM fermentável).

Means followed by different letters, small (row) and capital (column), are significantly different by $F$ test at $5 \%$ of probability.

${ }^{1}$ BWG - Estimated daily body weight gain: high (1 kg/animal) and low (0.5 kg/animal).

2 Estimated potential of microbial fermentation: high $111 \mathrm{~g}$ of microbial crude protein/MJ of fermentable metabolizable energy) and low (9.5 g ofmicrobial crude protein/MJ of fermentable metabolizable energy). 
eventualmente, apresentar padrão ingestivo variável, dada a natureza de arranjo da fibra em cada alimento. Bürguer et al. (2000) obtiveram ingestão diária de FDN de 49,31 g/ $/ \mathrm{kg}$ de $\mathrm{PC}^{0,75}$ por bezerros com $107 \mathrm{~kg}$ recebendo feno de coastcross suplementado com milho e farelo de soja nos níveis de 30 a $90 \%$ da MS. Os resultados descritos por esses autores apresentaram média mais próxima às deste trabalho que a média encontrada por Dias et al. (2000), sugerindo que o arranjo estrutural da FDN também pode causar variação na ingestão diária de forragem.

Véras et al. (2000), em estudo com tourinhos Nelore de $330 \mathrm{~kg}$, suplementaram feno de Brachiaria decumbens e coastcross para com concentrado em níveis que variaram de 25 a $75 \%$ da MS. O consumo diário de FDN em kg/animal, $\%$ do $\mathrm{PC}$ e g $/ \mathrm{kg}$ de $\mathrm{PC}^{0,75}$ foi de 4,$93 ; 1,27$ e 56,22 para $30 \%$ de MS do concentrado e de 4,26; 1,09 e 48,54 para 42,5\% de concentrado na MS da dieta. Os resultados obtidos com $30 \%$ de concentrado foram consideravelmente mais altos que os obtidos neste experimento.

$\mathrm{Na}$ avaliação do potencial de fermentação microbiana, exceto na ingestão de EE, neste caso, com maior média $(\mathrm{P}<0,05)$ nos animais com baixo potencial fermentativo, não foi verificada qualquer diferença $(\mathrm{P}>0,05)$ nas variáveis de ingestão das frações relacionadas à fração fibrosa da dieta.

Os dados de digestão parcial e total das diferentes frações das dietas, estimadas por meio da FDAi, são apresentados nas Tabelas 6 a 9. Não foi observada diferença $(\mathrm{P}>0,05)$ entre as médias de digestão ruminal para as diferentes frações. As dietas balanceadas para diferentes níveis de GPC proporcionaram similar coeficiente de digestão ruminal de $\mathrm{MS}, \mathrm{MO}, \mathrm{PB}, \mathrm{CT}, \mathrm{FDN}$ e FDA (Tabela 6).

O mesmo foi observado quando foram considerados os diferentes potenciais de fermentação microbiana. No caso da digestibilidade ruminal da fração EE, foram obtidas médias negativas, provavelmente em razão da contribuição endógena do rúmen e do abomaso, o que torna o fluxo intestinal maior que o fluxo oral (Sampaio et al., 2000). Ítavo et al. (2002e), utilizando FDAi como indicador, alimentaram machos Nelore (não-castrados com $165 \mathrm{~kg}$ de peso corporal) com feno de coastcross e níveis de concentrado de 20 a $80 \%$ da MS e verificaram digestibilidade ruminal da MS, MO, PB, EE, CT e FDN de 56,45; 62,49; 4,80; 1,$41 ; 71,36$ e 77,48\%, respectivamente. Algumas destas médias são bastante discrepantes dos valores apurados neste trabalho.

Não foram verificadas diferenças $(\mathrm{P}>0,05)$ em qualquer dos parâmetros de digestão intestinal avaliados. De forma análoga ao que ocorreu na digestibilidade ruminal, as suplementações para diferentes níveis de produção animal proporcionaram semelhantes coeficientes de digestão intestinal de MS, MO, PB, EE e CT. O mesmo foi observado quando considerados os diferentes potenciais de fermentação microbiana $(\mathrm{P}>0,05)$. Foram obtidas médias negativas de digestão intestinal para FDN e FDA, com semelhança $(\mathrm{P}>0,05)$ entre os tratamentos avaliados

A digestibilidade aparente total da MS diferiu $(\mathrm{P}<0,05)$ entre os níveis de produção dentro dos diferentes potenciais de fermentação (Tabela 8). Para cada potencial de

Tabela 5 - Ingestão diária das frações de carboidratos e lipídeos por tourinhos Santa Gertrudes recebendo feno de capim-marandu e concentrado para diferentes potenciais de fermentação e produção

Table 5 - Daily intakes of carbohydrates and fat on Santa Gertrudis young bulls fed diets containing palisadegrass hay plus concentrate formulated to yield different potential of microbial protein fermentation

\begin{tabular}{|c|c|c|c|c|c|c|c|}
\hline \multirow[t]{2}{*}{$\begin{array}{l}\text { Ingestão } \\
\text { Intake }\end{array}$} & \multicolumn{2}{|c|}{$\begin{array}{l}\mathrm{GPC}^{1} \\
B W G^{1}\end{array}$} & \multicolumn{3}{|c|}{$y^{(2)}$} & \multirow[b]{2}{*}{$\mathrm{F}$} & \multirow[t]{2}{*}{$\mathrm{CV}^{3}(\%)$} \\
\hline & $\begin{array}{l}\text { Baixo } \\
\text { Low }\end{array}$ & $\begin{array}{l}\text { Alto } \\
\text { High }\end{array}$ & $\mathrm{F}$ & $\begin{array}{l}\text { Baixo } \\
\text { Low }\end{array}$ & $\begin{array}{l}\text { Alto } \\
\text { High }\end{array}$ & & \\
\hline $\mathrm{CT}$ (kg/animal) ${ }^{4}$ (TCHO, kg/animal) & 5,56 & 6,25 & $*$ & 6,00 & 5,81 & NS & 3,28 \\
\hline FDN (kg/animal) $(N D F, k g /$ animal $)$ & 4,63 & 4,75 & NS & 4,67 & 4,71 & NS & 3,83 \\
\hline FDN (\% PC ) $(N D F, \% B W)$ & 1,14 & 1,18 & $*$ & 1,15 & 1,16 & NS & 3,40 \\
\hline $\mathrm{FDN}\left(\mathrm{g} / \mathrm{kg} \mathrm{PC} \mathrm{C}^{0,75}\right)\left(N D F, g / \mathrm{kg} B W^{0.75}\right)$ & 50,99 & 52,73 & NS & 51,62 & 52,09 & NS & 3,49 \\
\hline FDA (kg/animal) $(A D F, \mathrm{~kg} /$ animal $)$ & 2,59 & 2,59 & NS & 2,54 & 2,65 & NS & 4,64 \\
\hline $\mathrm{EE}(\mathrm{kg} /$ animal $)(E E, \mathrm{~kg} /$ animal $)$ & 0,158 & 0,165 & $*$ & 0,167 & 0,156 & * & 0,90 \\
\hline
\end{tabular}

NS - não-significativo; * significativo a $5 \%$ de probabilidade pelo teste $\mathrm{F}$.

$1 \mathrm{GPC}$ - Ganho diário estimado de peso corporal: alto (1 kg/animal) e baixo $(0,5 \mathrm{~kg} / \mathrm{animal})$.

2 y - Potencial estimado de fermentação microbiana: alto (11 g de PB microbiana/MJ de EM fermentável) e baixo (9,5 g de PB metabolizável/MJ de EM fermentável).

$3 \mathrm{CV}$ - Coeficiente de variação.

NS - not significant.; * -significant at $5 \%$ of probability by F test.

1 BWG-Estimated daily body weight gain: high (1 kg/animal) and low $(0.5 \mathrm{~kg} / \mathrm{animal})$

2 Estimated potencial of microbial fermentation: high (11 g of microbial crude protein/MJ of fermentable metabolizable energy) and low (9.5 g of microbial crude protein/MJ of fermentable metabolizable energy).

${ }^{3} \mathrm{CV}$ - coefficient of variation 
Tabela 6 - Digestibilidade ruminal de nutrientes da dieta ingerida por tourinhos Santa Gertrudes recebendo feno de capim-marandu e concentrado para diferentes potenciais de fermentação e produção (estimada pela fibra em detergente ácido indigestível)

Table 6 - Apparent ruminal digestibility of nutrients on Santa Gertrudis young bulls fed diets containing palisadegrass hay plus concentrate formulated to yield different potential of microbial protein fermentation

\begin{tabular}{|c|c|c|c|c|c|c|c|}
\hline \multirow[t]{2}{*}{$\begin{array}{l}\text { Digestibilidade ruminal (\%) } \\
\text { Apparent ruminal digestibility (\%) }\end{array}$} & \multicolumn{2}{|c|}{$\begin{array}{l}\mathrm{GPC}^{1} \\
B W G^{1}\end{array}$} & \multicolumn{3}{|c|}{$y^{(2)}$} & \multirow[b]{2}{*}{$\mathrm{F}$} & \multirow[t]{2}{*}{$\mathrm{CV}^{3}(\%)$} \\
\hline & $\begin{array}{l}\text { Baixo } \\
\text { Low }\end{array}$ & $\begin{array}{l}\text { Alto } \\
\text { High }\end{array}$ & F & $\begin{array}{l}\text { Baixo } \\
\text { Low }\end{array}$ & $\begin{array}{l}\text { Alto } \\
\text { High }\end{array}$ & & \\
\hline MS (DM) & 49,58 & 48,83 & NS & 48,40 & 50,01 & NS & 16,77 \\
\hline MO (OM) & 56,54 & 55,42 & NS & 55,13 & 56,84 & NS & 15,50 \\
\hline $\mathrm{PB}(C P)$ & 43,75 & 44,43 & NS & 41,93 & 46,25 & NS & 37,71 \\
\hline $\mathrm{FDN}^{4}(N D F)$ & 64,40 & 62,59 & NS & 63,44 & 63,55 & NS & 6,66 \\
\hline FDA $(A D F)$ & 61,00 & 57,81 & NS & 58,66 & 60,16 & NS & 10,10 \\
\hline
\end{tabular}

NS - não-significativo.

$1 \mathrm{GPC}$ - Ganho diário estimado de peso corporal: alto $(1 \mathrm{~kg} / \mathrm{animal})$ e baixo $(0,5 \mathrm{~kg} / \mathrm{animal})$.

2 y - Potencial estimado de fermentação microbiana: alto (11 g de PB microbiana/MJ de EM fermentável) e baixo (9,5 g de PB metabolizável/MJ de EM fermentável).

$3 \mathrm{CV}$ - Coeficiente de variação.

NS - not significant.

1 BWG - Estimated daily body weight gain: high (1 kg/animal) and low $(0.5 \mathrm{~kg} / \mathrm{animal})$.

2 Estimated potencial of microbial fermentation: high (11 g of microbial crude protein/MJ of fermentable metabolizable energy) and low (9.5 g of microbial crude protein/MJ of fermentable metabolizable energy).

${ }^{3} \mathrm{CV}$ - coefficient of variation.

Tabela 7 - Digestibilidade intestinal aparente de nutrientes (\% do não digerido no rúmen) da dieta ingerida por tourinhos Santa Gertrudes recebendo feno de capim-marandu e concentrado para diferentes potenciais de fermentação e produção

Table 7 - Apparent intestinal digestibility of nutrients on Santa Gertrudis young bulls fed diets containing palisadegrass hay plus concentrate formulated to yield different potential of microbial protein fermentation

\begin{tabular}{|c|c|c|c|c|c|c|c|}
\hline \multirow[t]{2}{*}{$\begin{array}{l}\text { Digestibilidade intestinal aparente (\%) } \\
\text { Apparent intestinal digestibility (\%) }\end{array}$} & \multicolumn{2}{|c|}{$\begin{array}{l}\mathrm{GPC}^{1} \\
B W G^{1}\end{array}$} & \multirow[b]{2}{*}{$\mathrm{F}$} & \multicolumn{2}{|c|}{$y^{(2)}$} & \multirow[b]{2}{*}{ F } & \multirow[t]{2}{*}{$\mathrm{CV}^{3}(\%)$} \\
\hline & $\begin{array}{c}\text { Baixo } \\
\text { Low }\end{array}$ & $\begin{array}{l}\text { Alto } \\
\mathrm{High}\end{array}$ & & $\begin{array}{c}\text { Baixo } \\
\text { Low }\end{array}$ & $\begin{array}{l}\text { Alto } \\
\text { High }\end{array}$ & & \\
\hline $\mathrm{MS}(D M)$ & 26,05 & 24,88 & NS & 26,14 & 24,78 & NS & 37,80 \\
\hline MO (OM) & 17,11 & 20,22 & NS & 19,17 & 17,97 & NS & 62,46 \\
\hline $\mathrm{PB}(C P)$ & 45,00 & 48,16 & NS & 44,10 & 49,07 & NS & 24,18 \\
\hline FDN (NDF) & $-4,55$ & $-3,62$ & NS & $-2,15$ & $-6,02$ & NS & $-366,36$ \\
\hline FDA $(A D F)$ & $-1,57$ & $-2,85$ & NS & $-1,83$ & $-2,59$ & NS & $-654,15$ \\
\hline
\end{tabular}

NS - não-significativo.

$1 \mathrm{GPC}$ - Ganho diário estimado de peso corporal: alto (1 kg/animal) e baixo $(0,5 \mathrm{~kg} / \mathrm{animal})$.

2 y - Potencial estimado de fermentação microbiana: alto (11 g de PB microbiana/MJ de EM fermentável) e baixo (9,5 g de PB metabolizável/MJ de EM fermentável).

$3 \mathrm{CV}$ - Coeficiente de variação.

NS - not significant.

${ }^{1}$ BWG - Estimated daily body weight gain: high (1 kg/animal) and low $(0.5 \mathrm{~kg} / \mathrm{animal})$.

2 Estimated potencial of microbial fermentation: high (11 g of microbial crude protein/MJ of fermentable metabolizable energy) and low (9.5 g of microbial crude protein/MJ of fermentable metabolizable energy).

${ }^{3} \mathrm{CV}$-coefficient of variation.

fermentação, foi observado que o tratamento para baixo GPC apresentou digestibilidade total da MS menor que o tratamento para alto GPC.

A fração protéica foi mais bem digerida no tratamento de alto potencial de fermentação e baixo GPC e no de alto nível de GPC e baixo potencial de fermentação. Os coeficientes de variação calculados foram 2,52 e 3,53\% para a digestibilidade aparente total de MS e PB, respectivamente.
Os resultados apresentados na Tabela 9 indicaram diferença $(\mathrm{P}<0,05)$ entre os tratamentos para GPC na digestibilidade total da MO. A digestão dos CT elevou-se $(\mathrm{P}<0,05)$ sob condições de maior GPC, o que não ocorreu para a digestibilidade da FDN e FDA e para a fração lipídica da dieta $(\mathrm{P}>0,05)$.

Véras et al. (2000) avaliaram dietas com fenos de Brachiaria decumbens e coastcross para tourinhos 
Tabela 8 - Digestibilidade aparente total da MS e PB da dieta ingerida por tourinhos Santa Gertrudes alimentados com feno de capim-marandu e concentrado para diferentes potenciais de fermentação e produção

Table 8 - $\quad$ Apparent total tract digestibility of dry matter (DM) and crude protein $(C P)$ on Santa Gertrudis young bulls fed diets containing palisadegrass hay plus concentrate formulated to yield different potential of microbial protein fermentation

\begin{tabular}{|c|c|c|c|}
\hline \multirow{2}{*}{$\begin{array}{l}\mathrm{GPC}^{1} \\
B W G^{I}\end{array}$} & \multicolumn{2}{|c|}{$y^{(2)}$} & Média \\
\hline & $\begin{array}{c}\text { Baixo } \\
\text { Low }\end{array}$ & $\begin{array}{l}\text { Alto } \\
\text { High }\end{array}$ & \\
\hline
\end{tabular}

Digestibilidade aparente da MS (\%)

Apparent DM digestibility (\%)

$\begin{array}{lllc}\text { Baixo (Low) } & 58,26 \mathrm{Ba} & 60,35 \mathrm{Ba} & 59,31 \\ \text { Alto (High) } & 65,37 \mathrm{Aa} & 63,11 \mathrm{Aa} & 64,24 \\ \text { Média (Average) } & 61,82 & 61,73 & -\end{array}$

Digestibilidade aparente da PB (\%)

Apparent CP digestibility (\%)

$\begin{array}{lllc}\text { Baixo (Low) } & 63,36 \mathrm{Bb} & 73,32 \mathrm{Aa} & 68,34 \\ \text { Alto (High) } & 73,14 \mathrm{Aa} & 75,52 \mathrm{Aa} & 74,33 \\ \text { Média (Average) } & 68,25 & 74,42 & -\end{array}$

Médias seguidas de letras distintas, minúsculas (linha) e maiúscula (coluna), diferem pelo teste $\mathrm{F}$ a $5 \%$ de probabilidade.

${ }^{1} \mathrm{GPC}$ - Ganho diário estimado de peso corporal: alto (1 kg/animal) e baixo (0,5 kg/animal).

2 y - Potencial estimado de fermentação microbiana: alto $(11 \mathrm{~g}$ de PB microbiana/MJ de EM fermentável) e baixo (9,5 g de PB metabolizável/ MJ de EM fermentável).

Means followed by different letters, small (row) and capital (column), are significantly different by $\mathrm{F}$ test at $5 \%$ of probability.

${ }^{1}$ BWG - Estimated daily body weight gain: high (1 kg/animal) and low $(0.5 \mathrm{~kg} / \mathrm{animal})$.

${ }^{2}$ Estimated potential of microbial fermentation: high $111 \mathrm{~g}$ of microbial crude protein/MJ of fermentable metabolizable energy) and low (9.5 g of microbial crude protein/M J of fermentable metabolizable energy).

Nelore de $330 \mathrm{~kg}$, e concentrado em níveis de 25 a 75\% da MS total. A digestibilidade total de MS, MO, PB, EE, CT e FDN foi de 61,$9 ; 63,3 ; 62,9 ; 65,0 ; 63,4$ e $51,5 \%$, e de 67,2 ; 68,$6 ; 72,3 ; 68,4$ e $53,4 \%$ para 30 e $42,5 \%$ de concentrado na MS da dieta, respectivamente. Considerando que utilizaram o mesmo indicador deste experimento, as médias calculadas por esses autores são coerentes com os resultados obtidos neste trabalho.

Em cinco grupos genéticos (Gir, Nelore, Guzerá, Caracu e Santa Gertrudes), Lançanova et al. (2001) obtiveram digestibilidade aparente total da MS e MO de 51,82 e $53,70 \%$, respectivamente, com dietas à base de feno de Brachiaria brizantha, milho e farelo de algodão, utilizando métodos de coleta total e lignina em detergente ácido. As médias encontradas por esses autores foram menores que as deste ensaio. Esses autores desenvolveram o experimento em baias coletivas, onde certamente houve competição para a ingestão dos alimentos, o que pode sugerir alguma explicação para essa diferença de resultados, mesmo que tenha sido utilizada a mesma raça.
Tabela 9 - Digestibilidade total aparente de nutrientes da dieta ingerida por tourinhos Santa Gertrudes alimentados com feno de capim-marandu e concentrado para diferentes potenciais de fermentação e produção

Table 9 - Apparent total tract digestibility of nutrients on Santa Gertrudis young bulls fed diets containing palisadegrass hay plus concentrate formulated to yield different potential of microbial protein fermentation

\begin{tabular}{|c|c|c|c|c|c|c|c|}
\hline & & & & & & & $\mathrm{CV}^{3}(\%)$ \\
\hline & $\begin{array}{c}\text { Baixo } \\
\text { Low }\end{array}$ & $\begin{array}{l}\text { Alto } \\
\text { High }\end{array}$ & $\mathrm{F}$ & $\begin{array}{c}\text { Baixo } \\
\text { Low }\end{array}$ & $\begin{array}{l}\text { Alto } \\
\text { High }\end{array}$ & $\mathrm{F}$ & \\
\hline $\begin{array}{l}\text { MO } \\
O M\end{array}$ & 61,57 & 66,63 & $*$ & 63,92 & 64,25 & NS & 2,73 \\
\hline $\mathrm{EE}$ & 58,57 & 58,83 & NS & 59,17 & 58,23 & NS & 8,45 \\
\hline $\begin{array}{l}\mathrm{CT} \\
\text { TCHO }\end{array}$ & 53,94 & 58,68 & $*$ & 56,86 & 55,77 & NS & 3,71 \\
\hline $\begin{array}{l}\text { FDN } \\
N D F\end{array}$ & 59,44 & 62,35 & NS & 62,07 & 59,72 & NS & 6,44 \\
\hline $\begin{array}{l}\text { FDA } \\
A D F\end{array}$ & 56,60 & 58,80 & NS & 57,86 & 57,53 & NS & 4,48 \\
\hline
\end{tabular}

NS - não-significativo, * - significativo a $5 \%$ de probabilidade.

${ }^{1} \mathrm{GPC}$ - Ganho diário estimado de peso corporal: alto (1 kg/animal) e baixo (0,5 kg/animal).

2 y - Potencial estimado de fermentação microbiana: alto $(11 \mathrm{~g}$ de PB microbiana/MJ de EM fermentável) e baixo (9,5 g de PB metabolizável/ MJ de EM fermentável).

${ }^{3} \mathrm{CV}$ - Coeficiente de variação.

NS - not significant, * - significant at $5 \%$ of probability.

${ }^{1}$ BWG - Estimated daily body weight gain: high (1 kg/animal) and low (0.5 kg/animal).

2 Estimated potencial of microbial fermentation: high $111 \mathrm{~g}$ of microbial crude protein/MJ of fermentable metabolizable energy) and low (9.5 g of microbial crude protein/MJ of fermentable metabolizable energy).

${ }^{3} \mathrm{CV}$ - coefficient of variation.

\section{Conclusões}

Dietas balanceadas para altos ganhos de peso, compostas por feno de capim-marandu e concentrado, foram vantajosas quanto à ingestão e digestão total de nutrientes para tourinhos confinados em relação àquelas formuladas para baixo nível de produção.

O balanceamento de dietas para diferentes potenciais de fermentação ruminal não parece ser justificável, pois não mostrou vantagens no aproveitamento das frações nutritivas e no seu perfil digestivo.

Em tourinhos mantidos em pastagens, a suplementação com concentrado formulado para altos ganhos de peso mostrou-se favorável quanto ao aproveitamento das frações nutritivas, o que ocorreu para dietas balanceadas para diferentes potenciais de fermentação ruminal.

\section{Literatura Citada}

AGRICULTURAL AND FOOD RESEARCH COUNCIL - AFRC.

Energy and protein requirements of ruminants. Wallingford: CAB International, 1993. 159p. 
AGRICULTURAL RESEARCH COUNCIL - ARC. The nutrient requirements of ruminant livestock. Farnham Royal: 1984. 45p. (suppl. 1).

ANUALPEC. Anuário da pecuária brasileira. São Paulo: FNP Consultoria \& Comércio, 2004. 376p.

ASSOCIATION OF OFFICIAL ANALYTICAL CHEMISTS AOAC. Official Methods of Analysis. 16.ed. Washington: 1995. v.1, p.1-30.

BERCHIELLI, T.T.; ANDRADE, P.; FURLAN, C.L. Avaliação de indicadores internos em ensaios de digestibilidade. Revista Brasileira de Zootecnia, v.29, n.3, p.830-835, 2000.

BRITO, R.M. Valor bioeconômico da suplementação alimentar para bovinos em pastagens de Brachiaria brizantha cv. Marandu. Jaboticabal: Universidade Estadual Paulista, 2004. 90p. Tese (Doutorado em Zootecnia) - Universidade Estadual Paulista, 2004

BÜRGUER, P.J.; PEREIRA, J.C.; COELHO DA SILVA, J.F. et al. Consumo e digestibilidade aparente total e parcial em bezerros holandeses alimentados com dietas contendo diferentes níveis de concentrado. Revista Brasileira de Zootecnia, v.29, n.1, p.206-214, 2000.

CARDOSO, R.C.; VALADARES FILHO, S.C; COELHO DA SILVA, J.F. et al. Consumo e digestibilidade aparentes totais e parciais de rações contendo diferentes níveis de concentrado, em novilhos F1 Limousin-Nelore. Revista Brasileira de Zootecnia, v.29, n.6, p.1832-1843, 2000.

DIAS, H.L.V.; VALADARES FILHO, S.C.; COELHO DA SILVA, J.F. et al. Consumo e digestões totais e parciais em novilhos $\mathrm{F} 1$ Limousin-Nelore alimentados com dietas contendo cinco níveis de concentrado. Revista Brasileira de Zootecnia, v.29, n.2, p.545-554, 2000.

EUCLIDES, V.P.B.; EUCLIDES FILHO, K.; ARRUDA, Z.J. Alternativas de suplementação para redução da idade de abate de bovinos em pastagem de Brachiaria decumbens. Campo Grande: EMBRAPA/CNPGC, 1997. 25p. (Circular Técnica, 25)

FOX, D.G.; SNIFFEN, C.J.; O'CONNOR, J.D. et al. A Net Carbohydrate and Protein System for evaluating cattle diets. III - Cattle requirements and diet adequacy. Journal of Animal Science, v.70, n.10, p.3578-3596, 1992.

FU, C.J.; FELTON, E.E.; LEHMKUHLEI, J.W. et al. Ruminal peptide concentration to optimize microbial growth and efficiency. Journal of Animal Science, v.79, n.5, p.1305-1312, 2001.

ÍTAVO, L.C.V.; VALADARES FILHO, S.C.; SILVA, F.F. et al. Consumo, degradabilidade ruminal e digestibilidade aparente de fenos de gramíneas do gênero Cynodon e rações concentradas utilizando indicadores internos. Revista Brasileira de Zootecnia, v.31, n.2, p.1024-1032, 2002a (supl.).

ÍTAVO, L.C.V.; VALADARES FILHO, S.C.; SILVA, F.F. et al. Níveis de concentrado e proteína bruta na dieta de bovinos Nelore nas fases de recria e terminação:consumo e digestibilidade. Revista Brasileira de Zootecnia, v.31, n.2, p.1033-1041, 2002b (supl.).

ÍTAVO, L.C.V.; VALADARES FILHO, S.C.; SILVA, F.F. et al. Consumo e digestibilidade aparentes totais e parciais de nutrientes em novilhos alimentados com dietas contendo vários níveis de concentrado. Revista Brasileira de Zootecnia, v.31, n.3, p.1543-1552, 2002c (supl.).

ÍTAVO, L.C.V.; VALADARES FILHO, S.C.; SILVA, F.F. et al. Produção microbiana e parâmetros ruminais de novilhos alimentados com dietas contendo vários níveis de concentrado. Revista Brasileira de Zootecnia, v.31, n.3, p.1553-1561, 2002d (supl.).
ÍTAVO, L.C.V.; VALADARES FILHO, S.C.; SILVA, F.F. et al. Comparação de indicadores e metodologia de coleta para estimativas de produção fecal e fluxo de digesta em bovinos. Revista Brasileira de Zootecnia, v.31, n.4, p.1833-1839, $2002 \mathrm{e}$.

LANÇANOVA, J.A.C.; OLIVEIRA, M.D.S.; PACOLA, L.J. et al. Digestibilidade aparente da matéria seca, matéria orgânica e energia bruta e nutrientes digestíveis totais de uma ração completa pata bovinos de diferentes grupos genéticos. Revista Brasileira de Zootecnia, v.30, n.3, p.897-903, 2001

LEÃO, M.I.; COELHO DA SILVA, J.F. Técnica de fistulação de abomaso em bezerros. In: REUNIÃO ANUAL DA SOCIEDADE BRASILEIRA DE ZOOTECNIA, 17., 1980, Fortaleza. Anais.. Fortaleza: Sociedade Brasileira de Zootecnia, 1980. p.37.

NATIONAL RESEARCH COUNCIL - NRC. Nutrient requirements of beef cattle. Washington, D.C.: National Academy Press, 1984. 90p.

NATIONAL RESEARCH COUNCIL - NRC. Nutrient requirements of beef cattle. Washington, D.C.: National Academy Press, 1996. $241 \mathrm{p}$.

PENNING, P.D.; JOHNSON, R.H. The use of internal markers to estimate herbage digestibility and intake. 2. Indigestible acid insoluble fiber. Journal of Agricultural Science, v.100, n.1, p.133-138, 1983 .

RESENDE, F.D.; QUEIROZ, A.C.; OLIVEIRA, J.V. et al. Bovinos mestiços alimentados com diferentes proporções de volumoso:concentrado. Digestibilidade aparente dos nutrientes, ganho de peso e conversão alimentar. Revista Brasileira de Zootecnia, v.30, n.1, p.261-269, $2001 \mathrm{a}$.

RESENDE, F.D.; QUEIROZ, A.C.; OLIVEIRA, J.V. et al. Bovinos mestiços alimentados com diferentes proporções de volumoso:concentrado. Efeito sobre a ingestão de nutrientes. Revista Brasileira de Zootecnia, v.30, n.1, p.270-279, 2001b.

SAMPAIO, A.A.M.; VIEIRA, P.F.; BRITO, R.M. Digestão total e parcial de nutrientes em bovinos alimentados com ração contendo levedura, uréia e farelo de algodão. Revista Brasileira de Zootecnia, v.29, n.2, p.589-597, 2000.

SAMPAIO, I.B.M. Estatística aplicada à experimentação animal. Belo Horizonte: Fundação de Ensino e Pesquisa em Medicina Veterinária e Zootecnia, 1998. 221p.

SAN THIAGO, L.R.; SILVA, J.M. O que você deve saber sobre suplementação em pasto na seca. Campo Grande: Embrapa Gado de Corte, 1998 (Gado de Corte Informa, v.11, n.1).

SNIFFEN, C.J.; O'CONNOR, J.D.; Van SOEST, P.J. et al. A net carbohydrate and protein system for evaluating cattle diets: II. Carbohydrate and protein availability. Journal of Animal Science, v.70, n.11, p.3562-3577, 1992.

STATISTICAL ANALYSIS SYSTEM - SAS. User's guide: statistics. Cary: 2001. (CD-ROM)

Van SOEST, P.J.; WINE, R.H. Use of detergent in the analysis of fibrous feeds. IV. Determination of plant-cell wall constituents. Journal of Animal Science, v.76, n.10, p.2717-2729, 1998.

VÉRAS, A.S.C. ; VALADARES FILHO, S.C. ; COELHO DA SILVA, J.F. et al. Consumo e digestibilidade aparente em bovinos Nelore, não-castrados, alimentados com rações contendo diferentes níveis de concentrado. Revista Brasileira de Zootecnia, v.29, n.6, p.2367-2378, 2000 (supl. 2). 